\title{
El poder se mutre de dogmas. El apropiacionismo en la obra de Herman Braun-Vega
}

\section{The Power is Nourished by Dogmas. The Appropri- ation in the Work of Herman Braun-Vega}

\author{
María Alexandra Guerrero Zegarra \\ Universidad Peruana de Ciencias Aplicadas, Lima, Perú \\ Contacto: maria.guerrero@upc.edu.pe \\ https://orcid.org/0000-0002-5193-2073
}

\section{RESUMEN}

El presente artículo tiene por objeto demostrar, dentro de las artes visuales, el papel del apropiacionismo como principio de articulación en la obra del artista plástico peruano Herman Braun-Vega, a través de los elementos y personajes tomados por el artista a partir de la Historia del arte occidental. Concretamente, se analiza la propuestas estética e ideológica de la obra El poder se nutre de dogmas (Velásquez [sic], Huamán Poma de Ayala, El Greco) (2006), y se concluye que la imagen adquiere un nuevo significado por el apropiacionismo de la figura, en tanto que es recontextualizado y reinterpretado, ya que el apropiacionismo en la obra de este artista tiene un fin de relectura/re-articulación de la memoria (individual, sociopolítica e histórica). Esto se pone en evidencia a través de la narrativa visual y la función del discurso político y religioso que contienen las imágenes de las cuales se apropia. La libertad creadora de Herman Braun-Vega se pone en evidencia en cuanto modifica los elementos plásticos y estructuras compositivas de obras que forman parte de la historia del arte occidental, y la reproducción de personajes y elementos representados, los que retrata con gran maestría en la pintura, con la finalidad de lograr una unidad en el espacio pictórico.

Palabras clave: Apropiacionismo; Pintura occidental; Iconográfico; Imágenes; Herman Braun-Vega

\section{ABSTRACT}

The purpose of this article is to demonstrate, within the visual arts, the role of appropriations as a principle of articulation in the work of the Peruvian plastic artist Herman Braun-Vega, through the elements and characters taken by the artist from History of Western Art. The aesthetic and ideological proposals of the work are analyzed of the work Power is nourished by dogmas (Velásquez [sic], Huamán Poma de Ayala, El Greco) (2006). It is concluded that the appropriation of the image makes a new meaning in the work, while it is recontextualized and reinterpreted, because the appropriations in the work of this artist has the intention of make a rearticulation of the memory (individual, sociopolitical and historical). These images that are appropriations were evidenced through the visual narrative and the function of the political and religious discourse that is contained in them.

Keywords: Appropriation; Western painting; Iconographic; Images, Herman Braun-Vega 


\section{Introducción}

En la década de 1980 surgieron, en el ámbito de las artes visuales, diversos conceptos sobre apropiacionismo que fueron planteados como una práctica artística de resignificación por la que el artista incorpora una imagen en un contexto diferente y consigue transformar la original en una nueva obra de arte. Se considera que, como principio articulador, se demuestra el papel apropiacionista en la obra de Herman Braun-Vega (Lima, 1933-París, 2019). Se considera que el apropiacionismo en la obra de este artista tiene un fin de relectura/re-articulación de la memoria (individual, sociopolítica e histórica). Además, se plantean aspectos que demarcan una relación entre el artista y el arte, un relato construido a partir de motivos ya representados, desde alusiones a temas históricos del siglo XVII, como temas de bodegones, costumbristas y retratos, hasta obras correspondientes a las vanguardias artísticas del siglo XX. Las propuestas indicadas anteriormente se desarrollan entre 1600 y 1960 y están presentes en el proyecto estético del arte contemporáneo dentro de la obra pictórica de Braun-Vega.

El objetivo general de esta investigación es demostrar, dentro de las artes visuales, el papel del apropiacionismo como principio de articulación en la obra de arte del artista plástico peruano Herman Braun-Vega, a través de los elementos y personajes de la historia del arte occidental de los cuales se apropia. Así mismo, se establece un proceso de resemantización de su obra de arte, ya que se aprecia un cambio marcado a nivel semántico y visual de sus productos previos, asignándole nuevos significados desde la narrativa visual del trabajo plástico. Una construcción de narrativa visual que se compone de representaciones del pasado, de obras de la pintura occidental y de situaciones cotidianas que se instalan en el presente. En tal sentido, los objetivos específicos son, en primer lugar, identificar los elementos y personajes de la historia del arte occidental en la obra El poder se nutre de dogmas (Velásquez [sic], Huamán Poma de Ayala, El Greco), de los cuales se apropia Braun-Vega; en segundo lugar, examinar la función del apropiacionismo a través de la propuesta estética e ideológica en la citada obra; en tercer lugar, evaluar la función del discurso político, social y religioso en relación con el apropiacionismo, que contiene las imágenes con las cuales Braun-Vega desarrolla su proceso artístico.
El acercamiento a la obra de Braun-Vega, en el presente trabajo, se articula a través de tres líneas bien diferenciadas: primero, el clásico método iconográfico e iconológico de Erwin Panofsky dado a conocer en El significado en las artes visuales (2004); segundo, los estudios acerca de la significación de la imagen de Michael Baxandall, propuesta en Modelos de intención. Sobre la explicación histórica de los cuadros (1989); y, finalmente, el estilo como expresión del artista de Heinrich Wölfflin, dado a conocer en Conceptos fundamentales en la Historia del Arte (2014).

La exploración y análisis se centra en dos perspectivas recientes sobre el concepto de apropiacionismo, definido por Juan Martín Prada en su libro $L a$ apropiación posmoderna. Arte, práctica apropiacionistas y teoría de la postmodernidad (2001), y en la obra de Douglas Crimp, titulada Posiciones críticas. Ensayos sobre las politicas del arte y la identidad (2005). Ambas usan el principio de resignificación para la práctica apropiacionista. Ese es el punto focal para el análisis de la obra del artista plástico Herman Braun-Vega. En suma, la importancia de esta investigación reside en la exploración y el análisis teórico sobre el tema desde la práctica apropiacionista. Además, puede ser un referente para el debate académico en torno a dicho tema en el arte peruano.

\section{Apropiacionismo}

Desde la década de 1980, el término apropiacionismo se ha definido en el campo del arte como el procedimiento dentro de las artes visuales por el cual la obra cita, copia, reconstruye, hibrida, manipula imágenes y les asigna nuevos significados. Padra (2001) afirma que el apropiacionismo es un movimiento artístico y cita elementos para la creación de una nueva obra. Dicho autor parte del propósito de la descontextualización y la deconstrucción a partir de imágenes ya existentes para generar un nuevo discurso. Ciertamente, ello se inicia desde que se separa un elemento de su contexto original y se logra una resignificación (Prada, 2001, p. 29).

Por su lado, Crimp (2005) establece que la apropiación implica una posición crítica y que el elemento que se copia se incluye en un nuevo contexto. De esta manera, la estrategia de la apropiación establece rela- 
ciones que se evidencian en las representaciones de la cultura contemporánea y en el valor del discurso en los cuales está inmerso (Crimp, 2005, p. 49).

Asimismo, se define un tipo de apropiación sobre el tratamiento de la obra de arte para su resemantización. Desde luego, esto resulta opuesto al carácter de originalidad y autenticidad. Para Ana María Guasch (2000), en su libro El arte último del siglo XX. Del postminimalismo a lo multicultural, "no se trata solamente de sustituir el sentido de cada imagen, sino de rehacerla en el sentido de que cada imagen y procedimiento pasaba a ser el espejo del mismo procedimiento y de la misma imagen" (p. 371). Por tanto, es evidente que hay una transformación del original en una nueva obra de arte.

\section{El apropiacionismo en la obra de Herman Braun-Vega}

Herman Braun-Vega nació en Lima, Perú, el 7 de julio de 1933. Fue hijo de don Francisco Braun, judío emigrado de Austria, y de doña Armida Vega, nacida en Iquitos. Su interés por el mestizaje parte de sus orígenes, tal como lo menciona cuando se refiere a la construcción genealógica de sus ancestros: "mi padre nació en 1902, en lo que en esa época era el Imperio austrohúngaro, y era judío. Mi madre nació en Iquitos, y era mestiza y protestante" (Braun-Vega, 2002, p. 166).

En cuanto a la proximidad a la pintura, desde su adolescencia, en Lima, se remonta a los recuerdos de las reproducciones colgadas en las paredes de su casa y a la determinación de su hermano mayor Max, que quería ser pintor. El crítico de arte y amigo con el que compartió años de juventud, Leslie Lee, en "Una semblanza familiar", publicada en el catálogo de la primera muestra de Braun-Vega en Madrid, señala:

[...] el papel que jugarán sus padres, especialmente don Francisco Braun, en la inclinación artística de todos sus hijos fue fundamental. Su casa, en la calle Independencia del balneario de Miraflores, tenía los muros de reproducciones de obras famosas, así como el lugar para reemplazar los paisajes, bodegas y retratos de sus dos hijos mayores. (1992, p. 78)
En 1950 ingresó a la Escuela de Bellas Artes del Perú y formó parte del taller de Carlos Quizpez Asín, integrante de la primera promoción de la escuela. Braun-Vega valoró las enseñanzas del maestro: "me aconsejó trabajar con la mano izquierda, pues, según él, mi mano derecha era más rápida que mi pensamiento" (2002, p. 168). A lo largo de año y medio, a través de reproducciones, se sintió influenciado por la pintura de Cézanne. Por ello, años más tarde, incorporó a su obra el retrato del artista, sus motivos y su estilo.

En 1951, con tan solo 17 años, Braun-Vega decidió viajar a Europa y se vio abstraído por la pintura occidental, que le sirvió como insumo para la creación. Cuando regresó a Lima, su pintura se perfeccionó, partiendo de los aportes del impresionismo y la gestualidad producida por el expresionismo de la escuela de Nueva York, a partir del denominado action painting. $\mathrm{Al}$ año siguiente, logró su primera exposición en el Salón de Otoño de París con una serie de bodegones; temática que desarrollará en el primer período gestual de su obra pictórica, el cual se caracterizó por el predominio de los colores neutros, uso de materiales pastosos y pinceladas libres y continuas que visualmente le dan un carácter mímico.

Hacia finales de la década de 1960 decidió regresar a París, donde vivió hasta su muerte (2 de abril de 2019). Se formó a partir del primer contacto con las obras expuestas en los museos, así como del diálogo con artistas de diferentes disciplinas con los cuales logró una comunicación incesante. Su pintura, incluso en esta década, siguió vinculada al tipo gestual. Paulatinamente se evidencia una apropiación de otros elementos que luego inserta en sus obras y se produce un estilo que desarrolló en los siguientes años.

En 1968, Braun-Vega visitó el entonces flamante Museo Picasso en Barcelona y quedó sorprendido por la serie de cuadros realizados por el artista catalán, haciendo referencia a Las Meninas de Velásquez [sic]. En tal sentido, el artista sostiene: "hacer mía la obra de otros es la gran lección que me ha dado Picasso" (2008, citado en Santa Cruz, 2010, p. 147). A su vez, en la entrevista concedida al historiador del arte César Octavio Santa Cruz, menciona su experiencia tras observar los cuadros de Picasso: "fue para mí muy impactante, porque vi lo que era posible hacer con la iconografia del pasado cuando la actualizas visual- 
mente" (2008, citado en Santa Cruz, 2010, p. 148). Después de todo, existe una dimensión histórico-crítica que plantea una visión específica de la pintura del pasado (Baxandall, 1989, s/p.).

Desde el año 2001 hasta la actualidad, diversos escritores e investigadores se han manifestado entre la descripción realizada por el artista y en reconocer las influencias artísticas occidentales en la obra. Asimismo, se nota claramente que califican la propuesta de Braun-Vega como "Nueva Figuración" y la analizan en comparación con el planteamiento del artista y la apropiación que hace de imágenes de la pintura occidental. Entre los más importantes, se encuentran Héctor Loaiza (2001) en "El sincretismo cultural en la obra de Herman Braun-Vega"; Elida Román (2003) en "Arte de Apropiación"; Roberto Gac (2003) en "Braun-Vega maestro de la interculturalidad"; JeanLuc Chalumeau (2003) en La nueva figuración. Une histoire de 1953 à nos jours; Zygmunt Bauman (2007) en Arte, ¿líquido?; Carmen Herrera Nolorve y Ricardo Tang-Andujar (2008) en "Conversando con Don Herman"; y César Octavio Santa Cruz (2010) en "Doble enfoque sobre Occidente, la influencia de Las Meninas en la obra de Herman Braun-Vega".

El pintor que su obra sea reconocida desde que realizó su primera exposición individual en la Galería Jueves, en Lima (1965), y su continuidad le ha permitido participar en un sinnúmero de muestras colectivas, en salones nacionales y en bienales de arte, como las de Venecia y São Paulo. Es considerado como uno de los pintores contemporáneos más importantes; en 1992 se le dedicó una muestra retrospectiva en el Museo Español de Arte Contemporáneo, en Madrid. En los últimos años ha participado en muestras individuales en países como Alemania, España, Francia, Marruecos e Israel.

En realidad, la atemporalidad en la obra de Braun-Vega permite ingresar a un espacio inexorable plagado de citas de los grandes maestros del arte occidental. La filiación del autor con referencias a la obra Rembrandt, Goya, Manet, Cézanne, Monet, Ingres, Matisse y Gauguin forma parte de la creación pictórica del artista, y reflexiona en el insondable acto creativo que seduce al espectador. Su trabajo se inicia con un análisis de la obra de Velásquez [sic], Picasso y Cézanne, con los que ha construido un universo de personajes que dialogan en un mismo espacio pictó- rico. Así, realiza una estructura de la historia en los ámbitos social y político, y contextualiza hasta lo cotidiano. En tal sentido, señala: "mi obra debe ser testimonial, que interpole la memoria del espectador para que este, con su mirada y reflexión, pueda recrearla de acuerdo con sus vivencias" (Braun-Vega, 2002, s/p). En definitiva, el contenido conceptual y narrativo en la obra debe destacar su valor testimonial y establecer la vía de enlace con el espectador.

Las tensiones visuales que logra el espacio pictórico ponen en evidencia, por un lado, las referencias a la cultura latinoamericana, una creación quizás originada en su propia condición de mestizo; y, por otro, las relaciones que, como autor, establece con las imágenes que cita de la pintura occidental. Así, la figura de Herman Braun-Vega cobra valor extraordinario porque su trabajo pictórico y la prolongada y reconocida actividad artística pueden considerarse como un reflejo de su pensamiento, postura y su reflexión acerca del arte. Especialmente, se caracteriza por plasmar en sus obras su percepción sobre el mestizaje y el sincretismo existente en el arte peruano y occidental; igualmente, transmite su pensamiento ante la diversidad cultural. En tal sentido, se observa a Braun-Vega como un pintor que demuestra su extraordinaria capacidad artística, pensamiento integrador y juicio crítico para cuestionar la contemporaneidad de la obra de arte.

\section{El poder se nutre de dogmas (Velásquez [sic], Guamán Poma de Ayala, El Greco)}

La obra pictórica de Herman Braun-Vega titulada El poder se nutre de dogmas (Velásquez [sic], Guamán Poma de Ayala, El Greco) de 2006 (figura 1) es un acrílico sobre tela que mide $116 \mathrm{~cm}$ de ancho por $89 \mathrm{~cm}$ de alto; por lo tanto, presenta un formato rectangular. Actualmente, forma parte de la colección particular del artista, en Francia.

\subsection{Nivel preiconográfico}

En el nivel de descripción preiconográfica de la obra El poder se nutre de dogmas (Velásquez [sic], Guamán Poma de Ayala, El Greco) (2006a), se observa un desarrollo compositivo con algunas diferencias en lo que corresponde a la configuración entre la obra de Herman Braun-Vega y su principal referencia: la obra de Velásquez [sic]. 


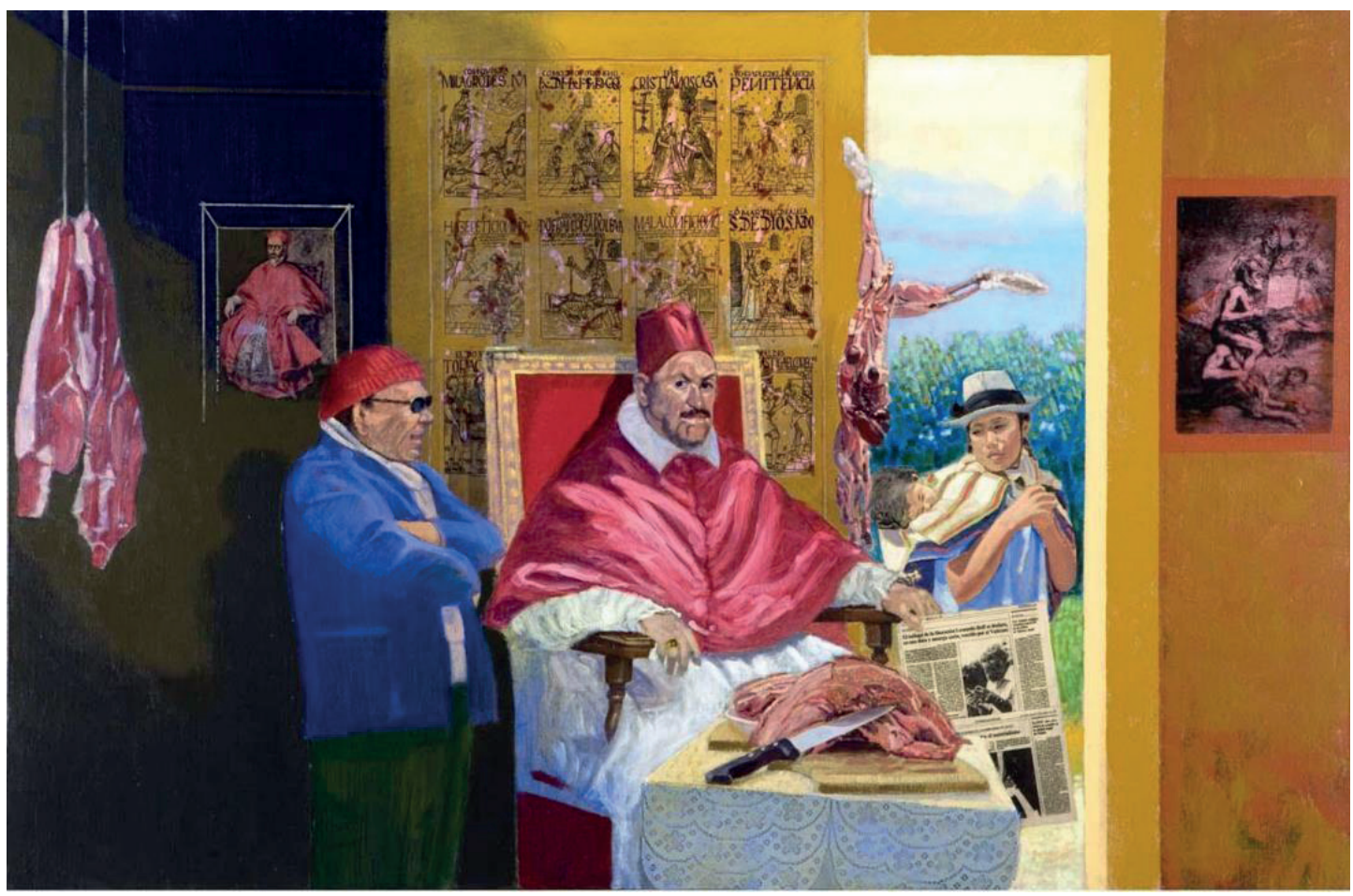

Figura 1. Braun-Vega, H. (2006a). El poder se nutre de dogmas (Velásquez [sic], Guamán Poma de Ayala, El Greco). Acrílico sobre tela, 116 x $89 \mathrm{~cm}$. Fuente: sitio oficial de Herman Braun-Vega.

En un formato rectangular y en una disposición horizontal, la obra muestra una habitación; en esta hay dos hombres en su interior, y en la entrada de la habitación, una mujer ingresa desde el exterior. En el interior, la escena está iluminada por una fuente de luz cenital y, en el exterior, por una fuente de luz solar que se esconde tras las nubes.

El marco de referencia en el que se encuentran los personajes de la obra es un área rectangular. En él se intersecta el eje horizontal y el eje vertical; por tanto, es aquí donde se establecen las relaciones espaciales de la composición. En el centro del cuadro y en el interior de una habitación se encuentra la figura de un hombre sentado sobre un sillón; está en posición de tres cuartos hacia su izquierda. Sus brazos se apoyan sobre el reposabrazos; la mano derecha sujeta un periódico y lleva un anillo en el dedo anular. Si bien el rostro no aparece frontal con respecto al espectador, dirige la mirada hacia su izquierda. Está sentado sobre una silla con un tapiz de tonalidades rojizas. Viste una muceta con botones sobre una sobrepelliz blanca y sobre su cabeza tiene un birrete. En primer plano, sus piernas se encuentran ocultas tras una mesa. Delante de él, en la parte inferior, se ubica una mesa cubierta con un mantel de encaje; sobre ella hay un trozo de carne cruda y un cuchillo de carnicero encima de una tabla. Detrás de él, en la parte superior, se observa un plano vertical con diez imágenes de grabados sobre la pared, que configuran una composición simétrica. Frente a él, en la izquierda, está un hombre parado de perfil con los brazos cruzados, quien viste con boina tejida, un saco y un pantalón largo, que observa al personaje central. En el fondo se distingue una puerta por donde ingresa una mujer indígena vestida con un sombrero sobre su cabeza; tiene un aguayo sujeto al cuello que ciñe sobre su espalda; además carga a un niño dormido del que solo se aprecia una porción de su cabeza y un vestido suelto. Detrás de los personajes, en el interior de la habitación, se distinguen dos cuadros en posición vertical: el que está ubicado al lado izquierdo está enmarcado linealmente sobre la pared y retrata a un hombre sentado que mira en dirección opuesta al personaje central de la obra. El que está ubicado al lado derecho es un grabado enmarcado sobre la pared. Del techo cuelgan, en el lado izquierdo, dos trozos grandes de carne cruda y sobre la mesa se aprecia el cuerpo de un animal degollado sujeto de la pata derecha. 


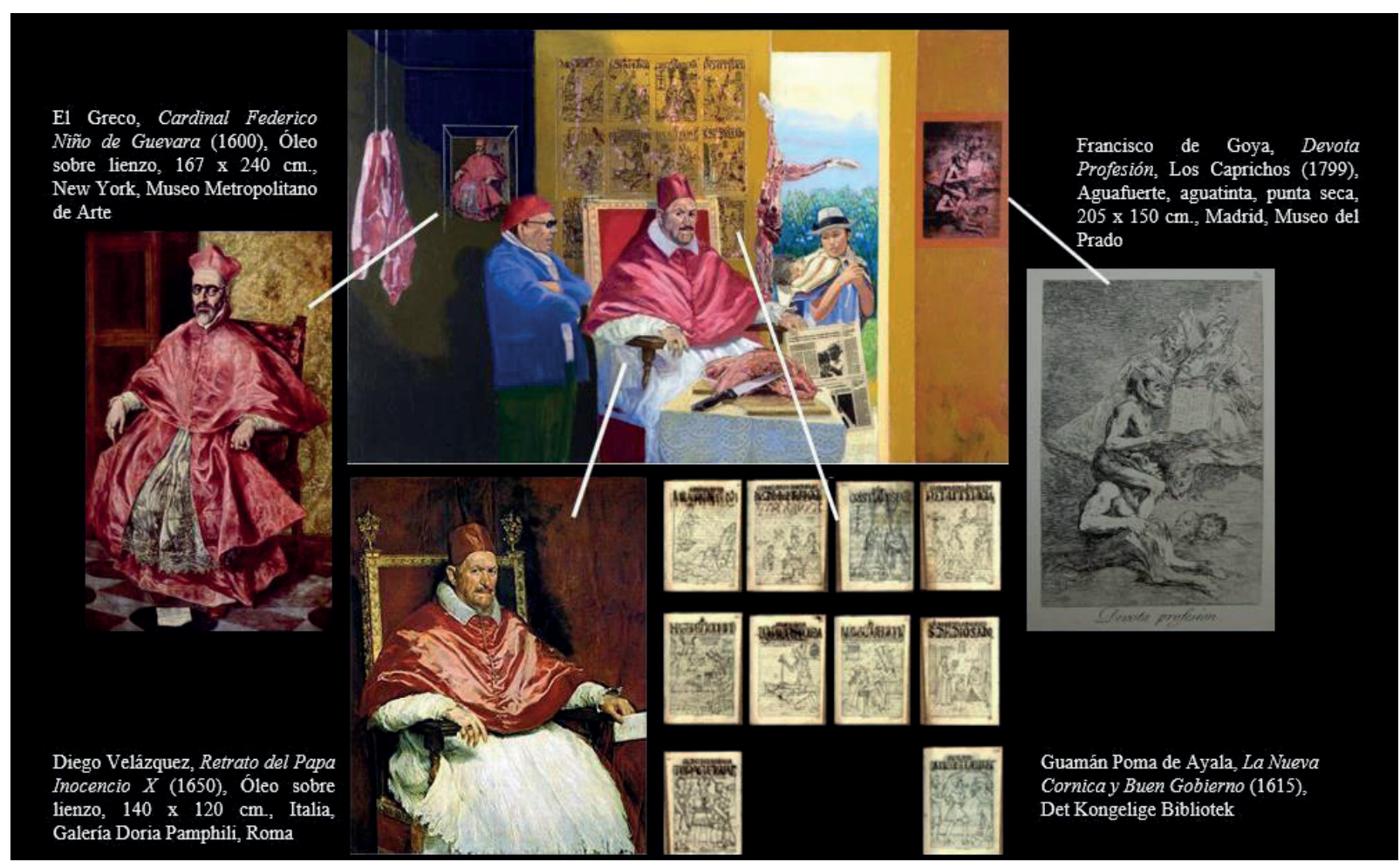

Figura 2. Elaboración propia a partir de las imágenes de Retrato del papa Inocencio X de Velásquez [sic], Devota profesión de Francisco de Goya, Cardenal Federico Niño de Guevara de El Greco, Nueva corónica y buen gobierno de Guamán Poma y El poder se nutre de dogmas (Velásquez [sic], Guamán Poma de Ayala, El Greco) de Braun-Vega.

\subsection{Nivel iconográfico}

En su composición, el cuadro contiene citas de Retrato del papa Inocencio $X(1650)$ de Velásquez [sic], cuya estructura retoma; también del Cardenal Federico Niño de Guevara (1600) de El Greco, de Devota profesión (1799) de Francisco de Goya y de la Nueva corónica y buen gobierno (1615) de Felipe Guamán Poma de Ayala. A su vez integra como personaje a una mujer indígena (figura 2).

En el centro de la composición se observa el Retrato del papa Inocencio X, de Diego Velásquez [sic] de 1650 (figura 3). El papa lleva, sobre la sobrepelliz blanca, la muceta con botones. Esta vestidura exterior de capa corta de seda cae formando grandes pliegues. Tradicionalmente es de color rojo y llega hasta la altura de los codos, que descansan sobre el reposabrazos de la silla de respaldar rojo en la que se encuentra sentado. Sobre su cabeza porta el birrete del mismo color.

Velásquez [sic] realizó el cuadro durante su segundo viaje a Italia entre 1649 y 1650. Figura en algunos documentos que el papa posó para el pintor en 1650:

El retrato del papa Inocencio X pintado por Velásquez [sic] en Roma entre 1649 y 1650, algo más de cien años después del de Pablo III de Ticiano. Nos recuerda que en la historia del arte el paso del tiempo no necesariamente implica un cambio de punto de vista. Podemos estar seguros de que Velásquez [sic] sentía el reto de aquella obra maestra, al igual que Ticiano se había sentido estimulado por el grupo de Rafael. Pero pese a la maestría con que dominaba los recursos de Ticiano, por el modo en que su pincel interpreta el lustre de la tela y la seguridad de toque con que capta la expresión del papa, no nos cabe la menor duda de que aquel hombre era así, y de que no estamos ante una fórmula bien ensayada. (Gombrich, 1999, p. 407)

En el cuadro original, Inocencio $\mathrm{X}$ sostiene con la mano izquierda un papel donde se lee: "alla santa di Nro Sigre / Innocencio X / Per / Diego de Silva / Velásquez [sic] de la Ca / mera di S. Mte Cattca". El cuadro se ha mantenido en propiedad de la misma ascendencia, primero en la familia Pamphili, y luego en la de Doria-Pamphili cuando ambas se unieron. Actualmente, se encuentra en la galería Doria-Pamphili de Roma, también conocida como Palazzo Doria-Pamphili. 


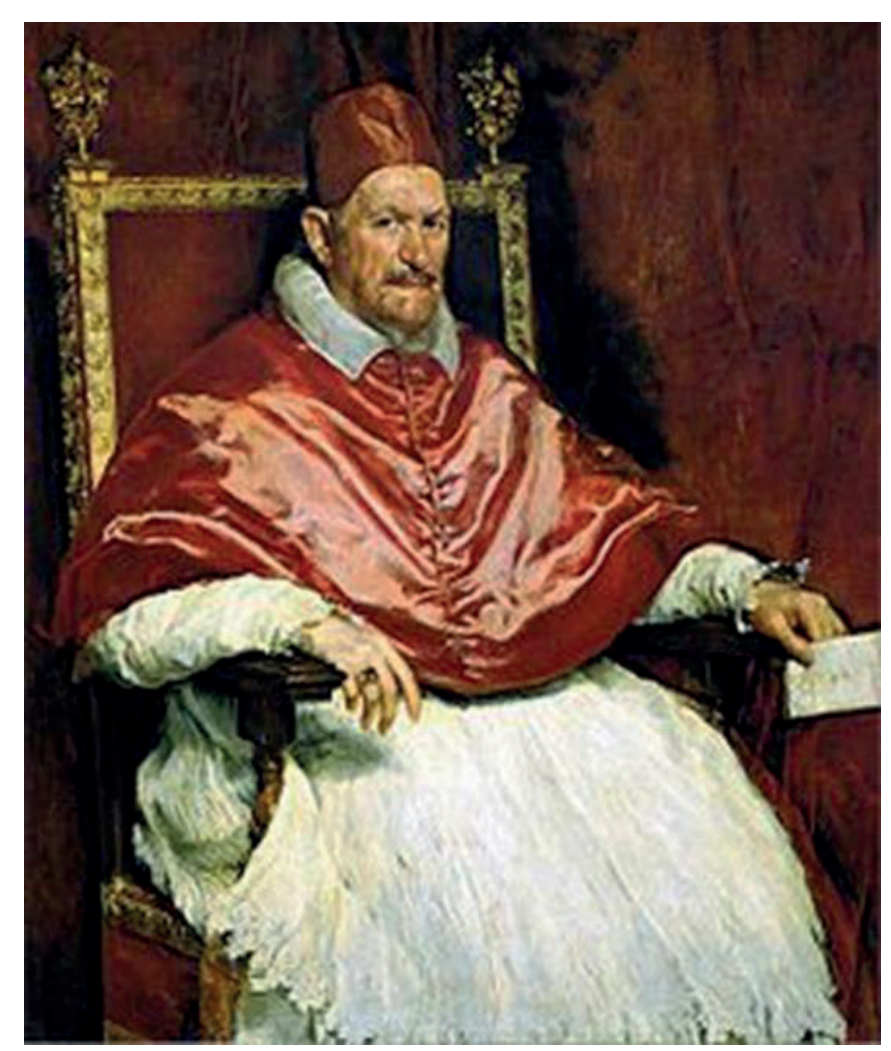

Figura 3. Velásquez [sic], D. (1650). Retrato del papa Inocencio X. Óleo sobre lienzo, $140 \times 120 \mathrm{~cm}$. Galería Doria Pamphili, Roma. Fuente: sitio del Palazzo Doria Pamphili.

A diferencia de la obra original, el papa Inocencio $\mathrm{X}$ sujeta un periódico con su mano izquierda. El titular es "El teólogo de la liberación". Se evidencia que Leonardo Boff se distancia, con una dura y amarga crítica, escrita por el Vaticano; debajo se ubica la fotografía de Leonardo Boff. El teólogo brasileño, exsacerdote franciscano condenado a un año de silencio obsequioso en 1985 por la Congregación de la Doctrina de la Fe tras la publicación de su libro Iglesia: carisma y poder. Ensayo de eclesiología militante, donde desarrolla sus ideas sobre la teología de la liberación y que en 1992 decide dejar la orden franciscana cuando estaba a punto de ser silenciado nuevamente. A la izquierda, de pie al lado de la silla ocupada por Inocencio X, proyectando una gran sombra en el interior, un fisgón con los brazos cruzados observándolo desde unos lentes oscuros.

De esta manera, al representar el cuadro Retrato del papa Inocencio $X$ pintado al óleo sobre lienzo, por Diego Velásquez [sic], durante su segundo viaje a Roma, y que fuera retratado cuando el primado tendría 66 años, se percibe que en esta pieza pictórica tiene un carácter de supremacía y simboliza el poder de la Iglesia católica. Tal como lo indica Ortega y Gasset (1987) en su libro sobre Velásquez [sic]:
[...] al terminar su retrato de Inocencio X, el papa le envía, como remuneración, una cadena de oro. Con inaudito gesto Velásquez [sic] la devuelve, haciendo saber que él no es un pintor, sino un servidor del rey, al cual sirve con su pincel cuando recibe orden de hacerlo. (p. 24)

A Velásquez [sic] se le atribuye la autoría de más de un ciento de pinturas que reflejan una clara exaltación por los monarcas de la Casa de Austria, las que fueron realizadas en la corte real española para Felipe IV, con importantes consecuencias en su obra. Tras el prolongado proceso por conseguir el título de Caballero de la Orden de Santiago, que obtuvo en 1658 por decisión de Felipe IV y la ayuda del mismo Inocencio X, Velásquez [sic] desarrolla gran actividad pictórica, por encargo, para las colecciones reales con los retratos y cuadros para la decoración del palacio.

Herman Braun-Vega (2006b) escribe, en una carta dirigida a Zygmunt Bauman que luego publicará en su libro Arte, ¿líquido? (2007)

[...] son ya 35 años que trabajo sobre la memoria, articulando sus distintos niveles: individual, sociopolítico e histórico [...] efectivamente creo que vivimos en un mundo sin memoria y esa es la razón por la que uno de los elementos que interviene en mi obra es la memoria, en esos tres niveles. (p. 102)

Esos tres niveles a los que hace referencia el pintor articulan un discurso donde se evidencia el poder que el Estado y la Iglesia han prolongado con su hegemonía y dominio. En diversos cuadros, el pintor alude al papa Inocencio X, ensaya cuestiones referentes a la postura de la Iglesia y la presencia de múltiples cuestionamientos en torno a las denuncias que debe enfrentar.

Desde 1981, Braun-Vega cita el retrato de Inocencio X en el desarrollo de su creación artística. Se puede ver en Hola, señor Bacon (Velásquez [sic]) de 1981; Amo la bomba de neutrones (Velásquez [sic]) de 1982; El laico (Velásquez [sic]) de 1984; Dar al César (Velásquez [sic], El Greco) (1992); El dinero de los Andes, o el diezmo del Vaticano (El Greco, Velásquez [sic], Guamán Poma de Ayala) de 2010. El cuadro al que hace referencia Braun-Vega (2003), en el libro de Zygmunt Bauman (2007), es Deja que los niños pequeños vengan a mi ... (Caravaggio) (figura 4): 
Ese cuadro representa, en verdad, al papa Inocencio X, pintado por Velásquez [sic]. Y lo que lee es un periódico que comenta la pedofilia en la iglesia de los EE. UU. En el ángulo superior izquierdo hay un efebo - pintado por Caravaggio, artista homosexual protegido por los dignatarios del Vaticano, entre los que estaba el futuro Inocencio X. En la mano izquierda del papa hay un periódico que menciona los escándalos de pedofilia en los que se vio envuelto el Vaticano en el 2003. La sonrisa forzada y la mano derecha levantada simulan una defensa o una excusa gestual, ¿que acaso se refiere a la actitud hipócrita de la iglesia ante la sexualidad? En el umbral de la puerta, en el fondo, se ve a un joven que lanza su dedo acusador contra él/nosotros. Delante del papa, hay un niño mordiendo una manzana: ¿la próxima víctima? Es un ejemplo de las tres memorias. (Bauman, 2007, p. 102)

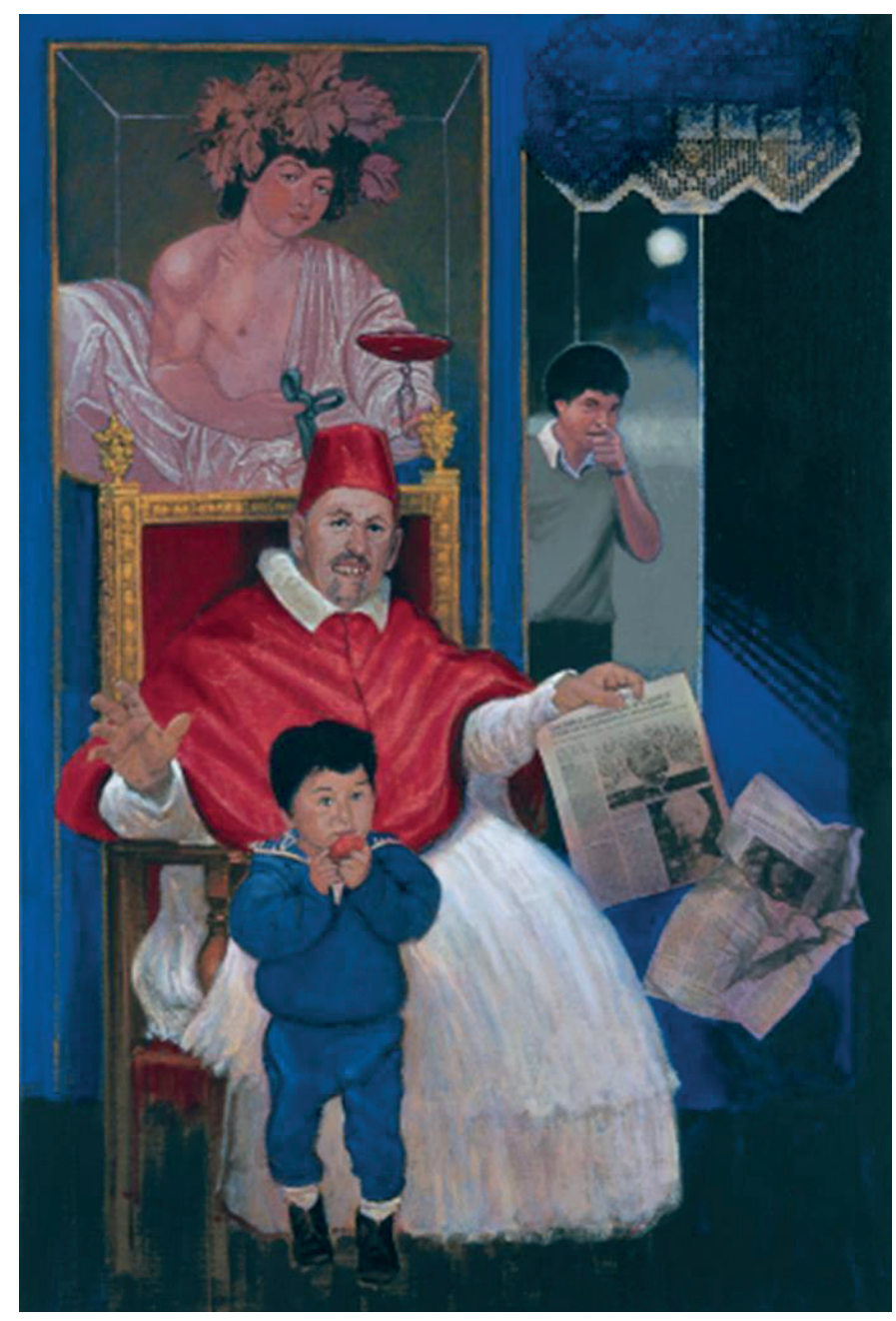

Figura 4. Braun-Vega, H. (2003). Deja que los niños pequeños vengan a mí... (Caravaggio). Acrílico sobre tela, $146 \times 96 \mathrm{~cm}$. Fuente: sitio oficial de Herman Braun-Vega.
El título de la obra hace alusión a las palabras de Jesucristo, cuando los apóstoles querían impedir que los niños se le acercaran. La elección de retratar al papa Inocencio X alude al poder ejercido por la Iglesia católica y su postura crítica a lo eclesiástico.

En el fondo, a la izquierda, sobre el muro de la habitación, está colgado el retrato del Cardenal Federico Niño de Guevara (figura 5) de El Greco (1541-1614). Con delineado inconcluso delimita el marco y, en la parte inferior, el retrato se integra con la pintura del muro. El pintor toledano es representante del manierismo, el movimiento espiritual y artístico más significativo de Europa. Cossío (1908), en su libro sobre El Greco, señala: "el Greco ha influido en Velásquez [sic], hay algo de Velásquez [sic] que procede de El Greco" (p. 512). La influencia de ambos artistas en la pintura española es a la que hace referencia Herman Braun-Vega cuando cita a los personajes retratados en su obra.

Nos encontramos aquí frente a un estilo privado
de ingenuidad, que orienta sus formas no tanto
por el contenido expresivo cuanto por el arte de
la época anterior, y en tal medida como hasta en-
tonces no había ocurrido con ninguna dirección
artística importante. La conciencia del artista se
extiende no sólo a la selección de los medios que
corresponden a su intención artística, sino tam-
bién a las determinaciones de esa misma inten-
sión. El problema teórico se refiere tanto a los
métodos artísticos como a los fines del arte. El
manierismo es, en este sentido, la primera orien-
tación estilística moderna ligada a un proble-
ma cultural y que estima que la relación entre
la tradición y la innovación es tema que ha de
resolverse por medio de la inteligencia. (Hauser,
1993, p. 11)

Tal como lo describe José Álvarez Lopera (1993) en su libro sobre El Greco, haciendo referencia al cardenal:

[...] procedente de la nobleza toledana, Niño de Guevara había sido miembro del Consejo de Castilla y Presidente de Cancillería de Granada antes de ser nombrado cardenal en 1596. En 1599 se convirtió en Inquisidor General y un año después en arzobispo de Sevilla. (p. 234) 


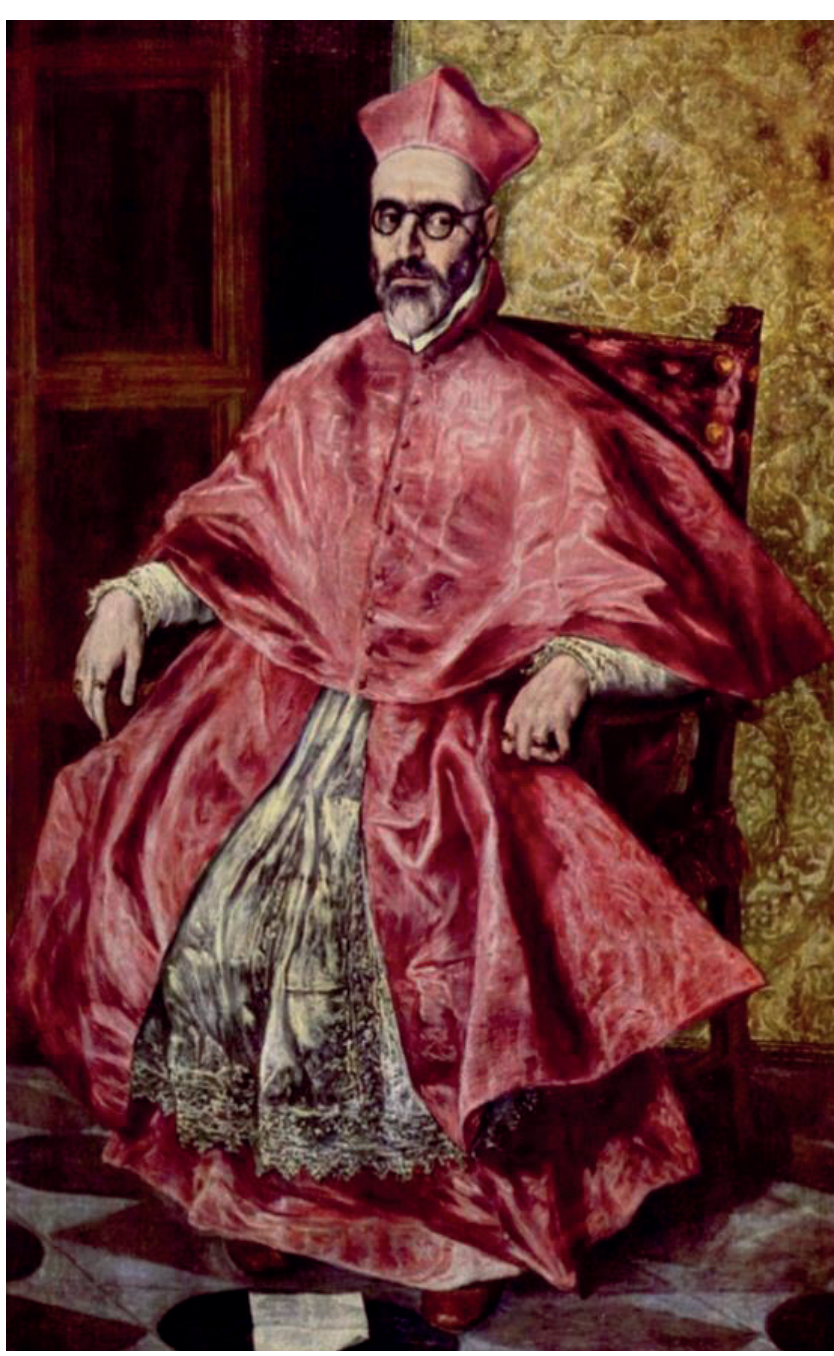

Figura 5. El Greco (1600). Cardenal Federico Niño de Guevara. Óleo sobre lienzo, 167 x 240 cm. Museo Metropolitano de Arte, Nueva York. Fuente: sitio oficial del Museo Metropolitano de Arte.

Para El Greco, la pintura del pontífice retrata el gesto determinante del inquisidor, que representa la autoridad y el poder de la Iglesia católica en el siglo XVII. Se restablece la inquisición como una reacción de la monarquía para proteger su poder y determinar las relaciones entre la Iglesia y el Estado, en la que el artista estaba inmerso y que realizaba para satisfacer los números encargos para el clero:

El cardenal aparece de cuerpo entero sobre un sillón frailero colocado en diagonal y teniendo como fondo una pared forrada de cordobán (que con sus tintes dorados hace el papel de tapiz de honor) y una puerta de rica madera. Está representado con todos sus atributos: birrete, hábito cardenalicio que al entreabrirse deja ver el alba, dos gruesos anillos en cada mano, zapatos rojos que como el terciopelo de sillón hace juego con el hábito... Y más que sentado parece estar asenta- do, tomando posesión de la silla y de todo cuanto lo rodea. (Álvarez, 1993, p. 234)

Esta puede ser la descripción del cuadro del papa Inocencio X, que se basa en el modelo prestigioso de representación de papas sentados, de poco más de medio cuerpo y a menudo con las manos sobre los brazos del sillón.

En el fondo, a la derecha, al lado de la puerta, hay un fragmento del muro sobre el que está colocado Devota profesión de 1799 (figura 6), aguafuerte de la serie Los caprichos de Francisco de Goya (1746-1828), pintor aragonés. A diferencia del grabado original, este es de color rojo. La serie de Los caprichos es la representación de la sátira política donde se reconoce a personajes de la vida pública en una época que culmina con la abdicación de Carlos IV.

Este es reconocido como uno de los períodos más fructíferos en la vida de Goya. La explicación de esta estampa del manuscrito del Museo del Prado señala:

¿Juras obedecer y respetar a tus maestras y superiores, barrer desvanes, hilar estopa, tocar sonajas, aullar, chillar, volar, guisar, untar, chupar, cocer, soplar, freír cada y cuando se te mande? Juro. Pues, hija, ya eres bruja, sea en hora buena. (Berea, 2007, p. 152)

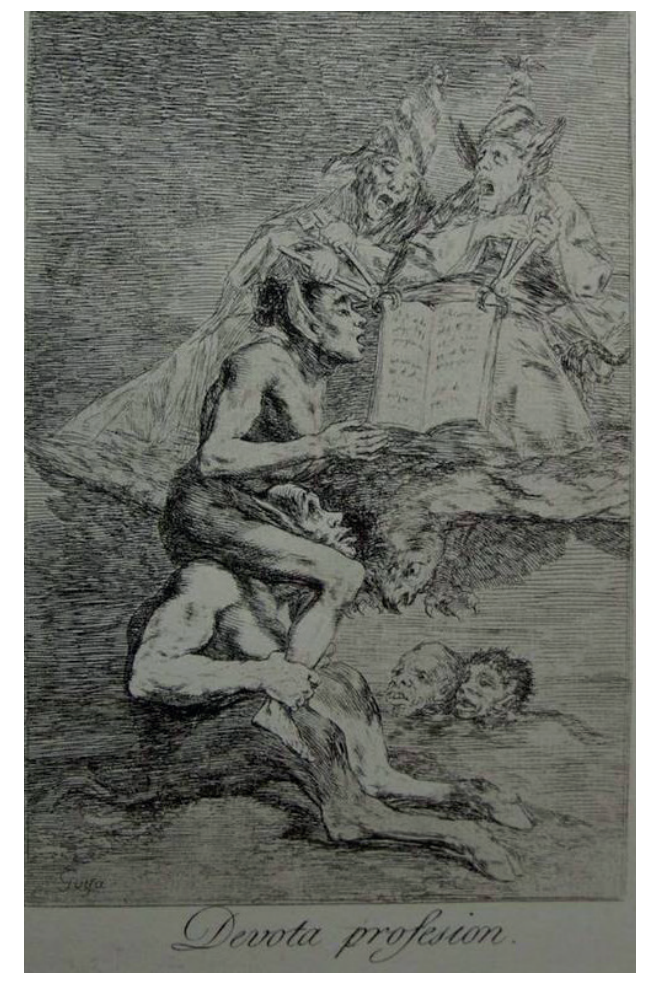

Figura 6. Goya, F. (1799). Devota profesión, parte de la serie Los caprichos. Aguafuerte, aguatinta, punta seca, $205 \times 150$ $\mathrm{cm}$. Museo del Prado, Madrid. Fuente: sitio oficial del Museo del Prado. 
Detrás del retrato de Inocencio X, sobre el muro, hay diez imágenes del manuscrito de Nueva corónica y buen gobierno de Guamán Poma de Ayala (1615), realizadas en collage (figura 7). Felipe Guamán Poma de Ayala (1535-1615) nació en Lucanas, Ayacucho; se presume descendiente, por su padre, de los antiguos reyes Yarovilca, de Huánuco, y, por su madre, de Túpac Yupanqui, el décimo inca. Fue el escritor indio que escribió la más importante crónica como interpretación de su historia utilizando los conocimientos occidentales de la cultura europea, la literatura teológica y obras clásicas, que había adquirido a partir de la relación con el extirpador Cristóbal de Albornoz, con el que trabajó en 1570 como intérprete cuando este fuera visitador eclesiástico de Lucanas. Tal como lo señala el historiador Antonio Zapata (2008) en el libro Historia y cultura de Ayacucho:

[...] siendo bastante mayor escribió la principal crónica redactada por un indio sobre el mundo andino precolombino y el impacto de la colonia en los Andes. Además, era un fino dibujante y acompañó su texto con 400 dibujos que lo han hecho muy famoso en nuestros días. (p. 95)

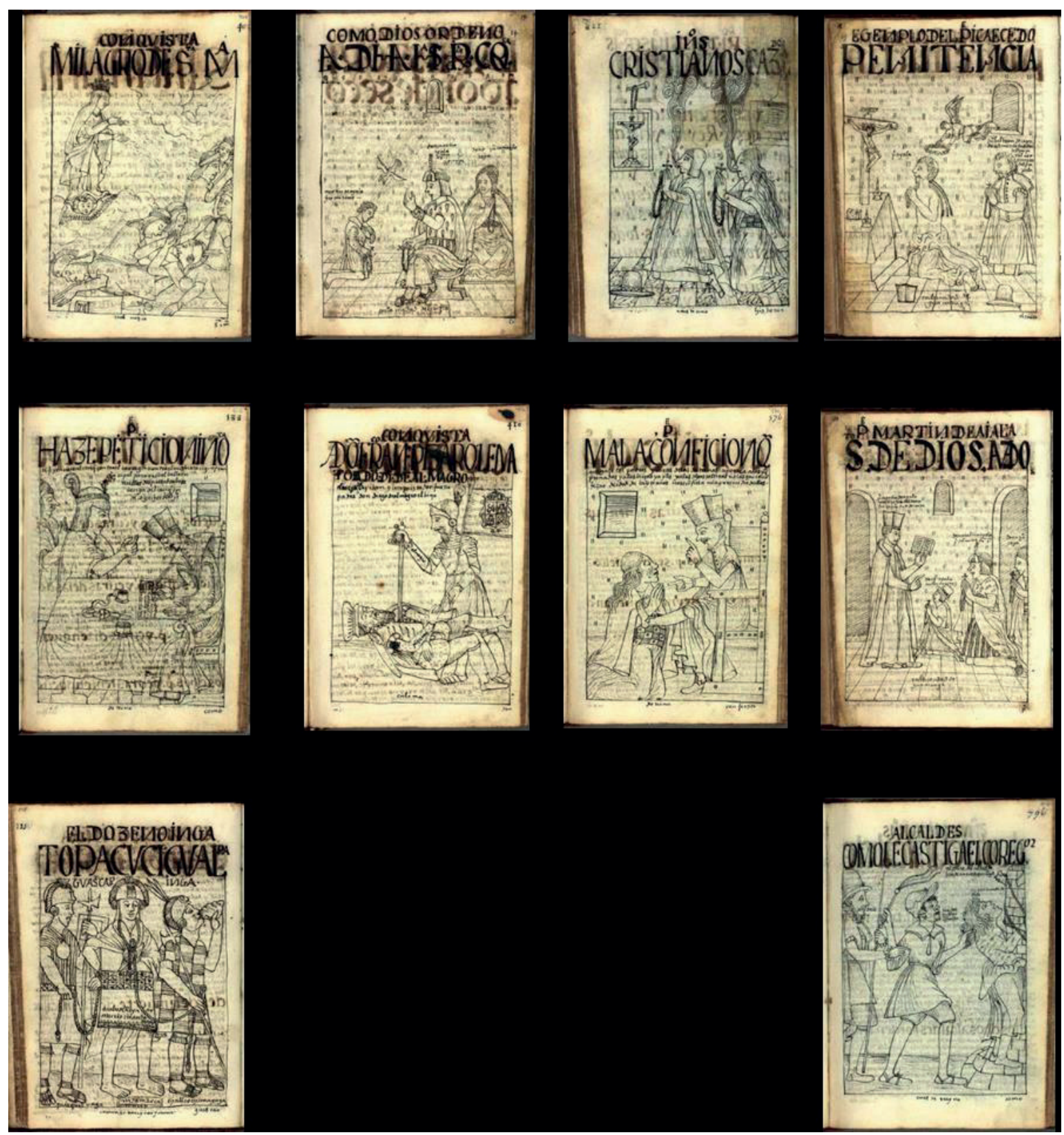

Figura 7. Guamán Poma de Ayala, F. (1615). Nueva corónica y buen gobierno.

Fuente: sitio oficial Det Kongelige Bibliotek. 
El códice, de más de un millar de páginas, fue encontrado en Copenhague, en la biblioteca del rey de Dinamarca, luego de estar perdido por más de cien años. Se desconoce cómo, luego de que llegase al rey de España, el manuscrito terminó en dicho país. Su redacción se inició cuando Guamán Poma fue desterrado de Huamanga, lugar en que vivió la mayor parte de su vida, luego de ser despojado de sus bienes $\mathrm{y}$ tras haber perdido sus tierras por varios juicios y sus derechos como curaca. Sirvió de intérprete en calidad de indio ladino. Por ello, su postura religiosa es mencionada por Zapata:

[...] aunque muy devoto de la religión cristiana, Wamán Poma fue enemigo de la Iglesia católica porque pensaba que los curas y doctrineros muchas veces violaban las normas que predicaban. El cronista indio amaba la coherencia y detestaba la hipocresía y el cinismo; opuso una actitud moral contra la decadencia que percibía en su tiempo. (2010, p. 95)

En la crónica se narra, mediante la imagen y el texto, los atroces abusos e injusticias que soportaban los indios bajo la dominación española. Fue, pues, una denuncia al poder político y religioso del cual Guamán Poma fue testigo en la Colonia. Resulta una fuente de información sobre el mundo indígena antes y después de la Conquista.

\subsection{Nivel iconológico}

Para realizar el análisis iconográfico, se plantea una interpretación partiendo de la escena que muestra el cuadro y de las temáticas a las que se genera una aproximación a Braun-Vega. La obra El poder se nutre estática con figuras en tensión. Se genera mayor peso visual a partir de los elementos y personajes implicados; se reconoce el retrato del papa Inocencio X en interacción con la mesa cubierta con un mantel y, sobre ella, el cuchillo junto al trozo de carne cruda que se encuentra en primer plano. Se observa también la figura del fisgón con los brazos cruzados, en segundo plano; la del cardenal Federico Niño de Guevara; las imágenes de la Nueva corónica y buen gobierno, que se aprecia en el plano posterior, y la mujer indígena que mira desde el exterior la escena con los personajes y elementos ubicados dentro de la habitación.

El retrato de Inocencio X, en segundo plano, está en posición de tensión, no solo porque se encuentra en el eje de sentido - este es el centro de la composición con la mayor proporción-, sino también por utilizar valores altos y el color en su vestimenta, que contrasta por la muceta de color rojo o el tapiz del sillón. En esta obra, Braun-Vega ha logrado darle al retratado una gran presencia y fortaleza por su complexión robusta, mientras que en el rostro la expresión con el ceño fruncido y enérgica mirada se dibujan rasgos de dureza y agresividad logrados con el contraste de luces y sombras en relación con los otros dos personajes de la obra.

Desde el enfoque de la presente indagación, se le otorga mayor presencia al papa Inocencio $\mathrm{X}$ vinculado con los personajes ordenados compositivamente, porque intensifican el contenido temático que otorga sustento a la interpretación desde el campo de la comunicación visual, la cual, a su vez, resulta de la propuesta plástica e ideológica y que integra la narrativa visual. Se considera que se le distingue porque

\section{Se propone una interpretación que resulta de los elementos plásticos y compositivos analizados. En primer lugar, se observa que se trata de una composición estática con figuras en tensión.}

de dogmas (Velásquez [sic], Guamán Poma de Ayala, El Greco) forma parte de una serie en la que el artista examina la presencia de la Iglesia católica en la pintura y su función evangelizadora en el Perú desde la Conquista.

Se propone una interpretación que resulta de los elementos plásticos y compositivos analizados. En primer lugar, se observa que se trata de una composición representa el poder de la Iglesia católica a través de la figura del sumo pontífice y la jerarquía eclesiástica que personifica. Al encontrarse su figura en el centro de la composición, se pone de manifiesto que lo representado es una identificación con los postulados de esa Iglesia, como la demostración poderosa al resguardo y el cumplimiento de sus dogmas. 
El rostro del pontífice se encuentra en tres cuartos y mira fijamente, de tal modo que se dirige al espectador del cuadro. Presenta una mirada que intimida ante la sumisión que ejerce el poder. De esta manera, no solo se ostenta el poder desde la mirada del retratado (dirigida al espectador), sino que también se percibe la tensión desde la mirada del personaje que aparece en el periódico que sujeta Inocencio X (fotografía de Leonardo Boff, teólogo de la liberación). El poder se basa en la coerción de toda su feligresía, que silencia todo propósito de cuestionar los abusos cometidos y que se viera reflejado en el castigo implícito cuando Leonardo Boff, el exsacerdote franciscano, fue condenado a un año de silencio obsequioso tras la publicación de su libro sobre el poder de la Iglesia, y que decide dejar la orden eclesiástica cuando se encuentra a punto de ser silenciado nuevamente.

Se evidencia la institucionalización de la Iglesia, que mantiene la relación de poder para invisibilizar y legitimar la autoridad, tras la investidura del papa, a lo largo de la historia. Este vínculo de los personajes permite apreciar el carácter de subordinación en interacciones menos enérgicas, como la contemplación del fisgón al observar al papa. Al respecto, es importante cuestionar si la función de vigilar se debe a un placer porque le otorga un carácter de exaltación y fervor acorde con la fe que se profesa. La segunda figura en tensión intensifica el discurso en ese sentido. En ella se observa la imagen del inquisidor, el cardenal Federico Niño de Guevara, que fue pintada por El Greco, acompañada por la serie de imágenes de la Nueva corónica y buen gobierno de Guamán Poma de Ayala.

Guamán Poma nació en 1535, y El Greco, en 1541. Ambos realizaron sus obras en fechas próximas. El primero publicó hacia 1615, el segundo en 1600. Ambos conocieron de cerca el poder que ejerce la Iglesia y sus obras reflejan el cumplimiento de sus dogmas. Demuestra que la interacción entre el hombre indígena y el poder del cardenal no es de complementariedad, sino que se basa en la jerarquía. Entre la cita de la obra de Goya y la de Guamán Poma, por ejemplo, no se trataría de indicar las diferencias que lo separan, sino de cómo, por diferentes vías, ambos lograron mostrar lo que representaba la Iglesia católica en España y en América, producto del proceso de evangelización del indio en el Perú.
Ello se anuncia con las representaciones de Guamán Poma de Ayala, quien refleja el impacto de la cultura española, ya que habla y escribe, aunque sea incorrectamente, y profesa la fe cristiana. Al parecer, ambos elementos eran fundamentales para trasformar el pensamiento indígena o bien conducirlo hacia un sincretismo religioso. Tal como lo señala Wachtel (2017), en su libro Sociedad e ideología. Ensayos de historia y antropología andinas, Guamán Poma cita de preferencia a Roma porque ahí reina el papa, "segunda persona de Dios", llamado también algunas veces "Monarca del Universo" (p. 207). También hace alusión a la dedicatoria al papa: "[...] muy alto sancto padre flaur del cielo y llaue del ynfierno poder de dios en el mundo sobre todos los emperadores y rreys monarca selestial" (Wachtel, 2017, p. 208).

En la obra estudiada, Herman Braun-Vega plantea el problema entre dos culturas, la occidental y la indígena, tal como lo hace Guamán Poma cuando inicia el manuscrito de su crónica. Así demuestra la dificultad que le significaba la lengua española mezclándola con el quechua, pero a la vez profesa la fe católica. De esta manera, se integran los aportes occidentales a las categorías indígenas; las adaptaciones y transformaciones que confiere las representaciones del espacio y del tiempo. La crónica refleja la experiencia de una vida de opresión ante los abusos que sufren los indios y las consecuencias de la Conquista. Asimismo, se comprende cómo un indio del Perú vive la dominación española.

\section{Conclusiones}

La obra de Braun-Vega aporta herramientas para su resignificación desde la producción contemporánea; ello a partir de la apropiación de imágenes de artistas occidentales para ser reconocidas como parte de la construcción identitaria. Igualmente, se distinguen elementos que permiten resemantizar la obra, por lo que se logra un giro en lo que respecta al contenido discursivo.

El análisis del cuadro mencionado a lo largo de este texto (figura 1), permite sustentar el discurso ideológico, a partir de la resignificación del contenido político, social y cultural, que se establece desde la conquista de América y la colonización europea. Se determinan las relaciones entre España y América Latina en busca de elementos que evidencien el mes- 
tizaje. Además, mientras que las imágenes establecen tensiones visuales para su recontextualización, el contenido de la obra alterna la lucha de poder, la colonización y la religión, aspectos que caracterizaron la relación entre ambos continentes. En la misma forma, el análisis de los elementos iconográficos adquiere una nueva significación, para legitimar la apropiación de las imágenes presentes en la obra aquí analizada. Finalmente, existe el interés de mostrar la búsqueda de citas de las cuales se apropia, para luego lograr la resignificación de la imagen, aspecto que caracteriza el estilo del artista.

Braun-Vega establece una relación con el espectador porque busca indagar en la memoria social, la memoria histórica y la memoria individual, e introducir todo esto en su obra para conseguir diversas lecturas visuales a partir de los distintos elementos iconográficos que añade a su obra. Esta proximidad se evidencia a través de su trabajo creativo, que nace de la apropiación hasta saber crear tensiones visuales que evoquen una representación inverosímil y convertirla en una proyección de sensaciones.

Sus obras pictóricas exhiben un grado de representación realista, en cuanto el estilo de la obra de la cual se apropia. Ello implica la intención de reflejar la realidad desde una conciencia estética que desarrolla durante trayectoria artística. Por lo tanto, su afán se dirige a la interpretación y lectura visual que está ligada a su propuesta plástica e ideológica. De esta manera, la originalidad del planteamiento artístico y el estilo de la obra de Herman Braun-Vega constituyen aspectos importantes en el lenguaje plástico del artista y brindan un nuevo abordaje en el análisis interpretativo que permiten su acercamiento a corrientes artísticas contemporáneas en el panorama artístico nacional, así como el reconocimiento de un notable creador.

\section{Referencias bibliográficas}

Álvarez, J. (1993). El Greco. Obra completa. Madrid: Silex.

Baxandall, M. (1989). Modelos de intención. Sobre la explicación histórica de los cuadros. Madrid: Hermann Blume.

Braun-Vega, H. (2002). Herman Braun-Vega (catálogo de la Maison de l'Amérique latine y del Centro Cultural de la Pontificia Universidad Católica del Perú). Lima: Editions d'art Somogy.

Braun-Vega, H. (2003). Deja que los niños pequeños vengan a mí... (Caravaggio) [imagen]. https://braunvega.com/picture?/132/category/17-2003_2000

Braun-Vega, H. (2006a). El poder se nutre de dogmas (Velásquez [sic], Guamán Poma de Ayala, El Greco [imagen]. https://braunvega.com/picture?/81/category/3-2007_2004

Braun-Vega, H. (2006b). Memorias. Pinturas y dibujos 1979-2006 (catálogo de la galería en el Castillo de Valderrobres y Museo Beurbier-Rossel en Montbéliard). Teruel: Museo de Teruel, Diputación de Teruel.

Chalumeau, J. L. (2003). La nueva Figuración. París: Cercle d’Art.

Cossío, M. B. (1908). El Greco. Madrid: Victoriano Suárez.

Crimp, D. (2005). Posiciones críticas. Ensayos sobre las políticas de arte y la identidad. Madrid: Akal.

El Greco. (1600). Cardinal Federico Niño de Guevara [imagen]. https://images.metmuseum.org/CRDImages/ep/original/DP-17777-001.jpg

Gac, R. (mayo-junio, 2003). Maestro de la interpicturalidad. Espacios Latinos, 208, 1-10.

Gombrich, E. H. (1999). La historia del arte. Buenos Aires: Sudamericana.

Goya, F. (1799). Devota Profesión, parte de la serie Los caprichos [imagen]. https:// www.goyaenelprado.es/obras/ficha/goya/devota-profesion/?tx_gbgonline_ pi1\%5Bgocollectionids\%5D=26\&tx_gbgonline_pi1\%5Bgosort $\% 5 D=d$

Guamán Poma de Ayala, F. (1615). Nueva corónica y buen gobierno [imagen]. http:// www.kb.dk/permalink/2006/poma/titlepage/es/image/?open=idp23904

Guasch, A. (2000). El arte último del siglo XX. Del posminimalismo a lo multicultural. Madrid: Alianza. 
Hauser, A. (1993). Historia social de la literatura y el arte. Barcelona: Editorial Labor. Herrera Nolorve, C. y Tang-Andujar, R. (2008). Conversando con Don Herman. Nudos. Revista de arte y letras de América Latina, 1, 21-24.

Lee, L. (1992, septiembre/diciembre). Una semblanza familiar. En H. Braun-Vega, Catálogo del Antiguo Museo Español de Arte Contemporáneo (pp. 78-79). Madrid: Ministerio de Cultura.

Loaiza, H. (2001, noviembre). El sincretismo cultural en la obra de Herman Braun Vega. Resonancias Literarias y Artísticas. https://braunvega.com/picture?/554

Ortega y Gasset, J. (1987). Papeles sobre Velásquez [sic] y Goya. Madrid: Alianza Editorial.

Panofsky, E. (2004). El significado en las artes visuales. Madrid: Alianza Editorial.

Prada, J. M. (2001). La apropiación posmoderna. Arte, práctica apropiacionistas y teoría de la Posmodernidad. Madrid: Fundamentos.

Román, E. (2003, 5 de enero). Arte de Apropiación. El Comercio, p. 29.

Santa Cruz, O. (2010). Doble enfoque sobre Occidente, la influencia de Las Meninas en la obra de Herman Braun-Vega. Escritura y Pensamiento, 2 (6), 149-160.

Velásquez [sic], D. (1650). Retrato del papa Inocencio X [imagen]. https://es.wikipedia. org/wiki/Palazzo_Doria-Pamphili\#/media/Archivo:Diego_Vel\%C3\%A1zquez_048b.jpg

Wölfflin, H. (2014). Conceptos fundamentales en la Historiā del Arte. Madrid: Austral.

Wachtel, N. (2017). Sociedad e ideología: ensayos de historia y antropología andinas. Lima: Instituto de Estudios Peruanos.

Zapata, A. y Rojas, R. (2008). Historia y cultura de Ayacucho. Lima: Instituto de Estudios Peruanos. 